\title{
Los 68: encuentro de muchas historias y culminación de muchas batallas*
}

\author{
Ricardo Pozas Horcasitas**
}

\section{Resumen}

El presente texto se mueve en el entramado de los eventos que fueron forjando la imagen y la representación de los sesenta por los habitantes de ese tiempo histórico, hasta desembocar en los movimientos estudiantiles de 1968, movimientos sociales que son su culminación y que condensan, política y culturalmente, las transformaciones surgidas durante la segunda posguerra mundial.

\begin{abstract}
In this essay the author wanders through the events that forged the image and the representation of the sixties, culminating in the 1968 student movements. These movements are the cultural and political condensation of the transformations that emerged in the post- World War II period.
\end{abstract}

Palabras clave: los sesentas, nuevos movimientos sociales, contracultura, feminismo, juegos olímpicos México.

Key words: the sixties, new social movements, counterculture, feminism, olympic games, Mexico.

* Agradezco a Blanca Beltrán la lectura de los muchos originales de este texto, a Leslie Guedulain y a Luciano Concheiro San Vicente la lectura y discusión del original y el apoyo en la búsqueda de la información. A este último agradezco, además, las cuidadosas traducciones de textos originales que forman el sino de la época.

** Doctor en Estudios Latinoamericanos por la Universidad Nacional Autónoma de México. Doctor en Sociología Política por la Escuela de Altos Estudios de París, Francia. Investigador Titular C de tiempo completo del Instituto de Investigaciones Sociales de la UNAM. 


\section{Introducción}

\section{Una década significa más que diez años}

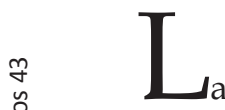

a década de los sesenta tiene como característica particular, a diferencia de los decenios anteriores, la de ser un decenio demográficamente joven, en expansión urbana y de servicios, en ampliación y diversificación creciente del consumo y con un crecimiento económico acelerado y sostenido. Este período estuvo inmerso en el entorno internacional de la Guerra Fría, uno de los momentos de mayor confrontación entre las dos metrópolis de ambos bloques, y en el inicio de una nueva forma de relación entre ellas, nombrada "coexistencia pacífica".

El presente texto se mueve en el entramado de los eventos que fueron forjando la imagen y la representación de los sesenta por los habitantes de ese tiempo histórico, hasta desembocar en los movimientos estudiantiles de 1968, movimientos sociales que son su culminación y que condensan, política y culturalmente, las transformaciones surgidas durante la segunda posguerra mundial. En más de un sentido la década termina ahí, tiempo en el que, los llamados "nuevos movimientos sociales", expresan los cambios en el sistema social, los límites de los regímenes políticos y el agotamiento del conjunto de recursos y relaciones establecidas entre el Estado Benefactor, la estructura socio económica y las modalidades de las organizaciones sociales y políticas que culminan en la crisis de 1973.

Los años sesenta están mayoritariamente poblados por jóvenes, los llamados baby boomers (Jones, 1980; Sauvy, 1969: 27 y ss.) y es por lo tanto, una década que gira en torno al futuro y en la cual, parte importante de esa población, los estudiantes de educación media y superior, son los políticamente más activos y culturalmente los más creativos. Los estudiantes representaban en cada sociedad nacional, el relevo de sus élites políticas, intelectuales y técnicas, pero sobre todo eran los depositarios de las expectativas del mejoramiento colectivo dado por el avance en la educación, el desarrollo tecnológico y la cultura. Ellos eran parte de la utopía y así se comportaron al forjar la suya.

Los jóvenes estudiantes eran concebidos por la generación adulta, por los sobrevivientes de la segunda guerra mundial y el Gran Crack (19291934), como los herederos de su esfuerzo, como los beneficiarios de las instituciones construidas por ellos para la paz y "el progreso" que se suponía 
deberían conservar junto con los beneficios del consumo extendido, que desde principios de los cincuenta, las sociedades habían alcanzado al convertir mayoritariamente la economía de guerra en economía de paz, productora masiva de bienes intermedios para el consumo. Desde la versión de la economía y teóricamente hablando, eran los niños del Welfare State.

Frente a la expectativa de la generación de los sacrificados, los jóvenes beneficiarios se volvieron rebeldes y no sólo renegaron del statu quo heredado sino que buscaron cambiarlo. A lo largo de la década de los sesenta va tomando forma la revuelta juvenil mundial que desemboca en 1968, en los llamados nuevos movimientos sociales (Pozas, 2006: 47).

Los nuevos movimientos estudiantiles tuvieron como característica común su fuerza contestataria y sus nuevas concepciones del contenido de la libertad, construida ésta a partir de la crítica y la revuelta conductual frente a las normas y valores establecidos que tejen el orden y la reproducción de las tradiciones instituidas. Estos movimientos protagonizados por los jóvenes eran, sobre todo, la ruptura del eje estructurador de los valores que mantienen vigentes la reproducción del orden social y su posibilidad de continuidad, a través de su aceptación y su validación cotidiana en las conductas de los miembros de las generaciones del relevo social.

En la sexta década del siglo XX, las sociedades metropolitanas y algunas periféricas o en vías de desarrollo, como las llamaba entonces la sociología, con su evolucionismo implícito, se encuentran en un proceso de crecimiento acelerado, con estabilidad macroeconómica y financiera. En el principio de los años cincuenta, se inicia un nuevo período de intenso desarrollo que alcanza incrementos nunca antes conseguidos: el $5.3 \%$ entre 1953 y 1963. A partir de este último año, el ritmo de crecimiento anual del PIB llega al 6.2\% hasta que se interrumpe en 1973, año en el que se ingresa a una nueva fase de desaceleración, la llamada Revolución de los Precios en la que aumenta cuatro veces el precio del petróleo, que había sido la fuente primaria de energía más barata por más de sesenta años (Pasquale, 1997: 93). En términos económicos este año es el final de las décadas de los cincuenta y sesenta conocidas como las décadas doradas del siglo XX.

La década de los sesenta, como todos los períodos intensos de la historia, es desbordada en sus orígenes e inconmensurable en sus influencias. Esta década es, como todas las otras unidades históricas sobrepuestas a la sucesión uniformizada y ascendente del tiempo, la formalización de un conjunto de procesos y eventos referidos a la cronología, que adquieren ubicación en la memoria colectiva. El acotamiento de los hechos en el tiempo, no rigidiza, ni delimita los contenidos de la historia al cuadrante del reloj. 
Esta década, stricto sensu, no son diez años, ni empieza en 1960 pero tampoco termina en 1970: es un ámbito temporal prioritario que identifica el sentido de un conjunto de eventos acaecidos en el tiempo, que forman una unidad de acciones políticas y sociales interconectadas, productoras de tendencias políticas y económicas identificables y constituyentes de representaciones sociales que dan significado cultural e identidad a una época. En ese tiempo, llamado los sesenta, se edificaron algunos de los más importantes relatos omnicomprensivos del siglo XX sobre la sociedad, el Estado y el individuo.

Los años sesenta fueron una década de intenso debate en la que se confrontan las ideologías como "sistemas intelectuales que reclamaban la verdad para sus concepciones del mundo" (Bell, 1988:19). Estos sistemas conceptuales conclusivos tendieron a establecer, en la práctica del ejercicio del poder institucional y organizativo de grupos sociales, una acción cultural de carácter autorreferencial, cuyo objetivo central era organizar a la sociedad con un proyecto previamente diseñado.

El modelo cultural del período intenso de la Guerra Fría estuvo sustentado en las ideologías binarias que dividían al mundo en democracia o comunismo. Este modelo cultural entró en un proceso de agotamiento representativo desde finales de los años cincuenta y culminó en los movimientos sociales de 1968, cuando las concepciones sobre las necesidades sociales e individuales ya no se realizan a través del modelo de bienestar propuesto por La Sociedad Opulenta (Galbraith, 1992); La Sociedad Postindustrial (Touraine, 1969); El advenimiento de la sociedad pos-industrial (Bell, 1973); El reto de la sociedad opulenta (Myrdal, 1962). Este modelo cultural, construido en la posguerra, va siendo confrontado por las nuevas necesidades de libertad social e individual. En el centro de esta confrontación en contra del modelo cultural vigente está la Contracultura, construida en un proceso de agregación de cambios de valores, de actitudes, de prácticas sociales y personales y de versiones particulares, que dan sentido a las acciones contestatarias de grupos en contra de lo establecido. Estos cambios de prácticas culturales fueron ejercidos por los grupos de jóvenes que en su acción colectiva fueron durante toda la década de los sesenta agregando y construyendo, a través de una nueva solidaridad social, nuevos sentidos del mundo. Proceso de cambio que culmina en la manifestación política internacional y sincrónica de los sesenta y ochos.

Las grandes ideologías omnicomprensivas de los años sesenta, construyeron los macro relatos de la historia y formaron la base teórica de los proyectos y programas políticos tanto de desarrollo como revolucionarios para el cambio del conjunto de la sociedad. A finales de los sesenta, es- 
tos relatos holísticos empezaron a ser desplazados por la construcción de proyectos de políticas - en plural- pragmáticas, tendientes a encontrar soluciones particulares a los problemas concretos y diferenciados entre sí de la sociedad.

La ideología del utilitarismo pragmático, constituida a partir del individualismo extremo concentró el sentido del tiempo social en el presente y no en la lucha por el futuro. La desagregación de lo social en lo individual fue desplazando a la versión totalizadora del mundo y corrió paralela al desplazamiento de la solidaridad social como el eje articulador de la moral pública que había tenido como sujeto social a los jóvenes. Este proceso de cambio cultural e intelectual enraizado en el borde final de la década de los sesenta fue propiciado por la crisis económica de 1973, que es uno de los cierres de la década de los sesenta en la que la representación de la centralidad del Estado, como Estado militar y social fue reemplazada por la ideología que puso en el centro de la regulación social al mercado, produciendo la revolución modernizadora con su eje ideológico de la planificación por especialidades, cada una con sus lenguajes cifrados. Este cambio desplaza los grandes proyectos transformadores por el pragmatismo de las agendas específicas.

\section{El principio fue antes}

La apertura de la década estuvo dada por un conjunto de eventos políticos significativos, uno de ellos sucede el 23 de octubre de 1956, con la invasión soviética a Hungría y revela el grado de represión con el que se consolidó el Estado Soviético, dirigido por los comunistas de la segunda generación, nomenklatura que en la política en el interior del bloque fustigó a Stalin pero que continuó con el estalinismo, erigiéndose como los constructores de la verdadera libertad frente a la libertad burguesa alienada. ${ }^{1}$

El gobierno soviético y antiestalinista revela su raigambre totalitaria y su tradición represora, que forma el universo de su cultura política, cuando el 23 de octubre de 1956 el premier Nikita Jruschov utiliza las tropas del Pacto de Varsovia y en nombre del comunismo internacional, la justicia proletaria y acusando a la revolución democratizadora húngara de fascista,

1 Nomenklatura nombra a la capa social que controlaba los mecanismos de poder y tomaba las decisiones políticas y administrativas sin estar sujeta a un control real por las instituciones formales. 
e inicia la ofensiva en contra del pueblo y el gobierno. Es el mismo Nikita que ocho meses antes, el 25 de febrero de ese año y como Primer Secretario del Partido Comunista de la Unión Soviética, en su informe leído al término del XX Congreso - a puerta cerrada y en ausencia de periodistas e invitados de otros países pero cuyo contenido se dio a conocer dentro y fuera de la URSS - denuncia los crímenes y errores de Iósif Stalin, el culto a la personalidad y el dogmatismo ideológico:

En vez de probar su corrección política y de movilizar a las masas, con frecuencia, escogió el camino de la persecución y de la aniquilación física, no sólo contra enemigos verdaderos, sino también contra individuos que no habían cometido crimen alguno contra el gobierno o contra el Partido. Aquí no vemos signo alguno de sabiduría, sino más bien de esa fuerza bruta que tanto alarmó a Lenin. ${ }^{2}$

Esta posición política fue acompañada de medidas político-administrativas que borraron la presencia iconográfica de Stalin en la vida social de la URSS y de los países del bloque. ${ }^{3}$ El proceso de desestalinización causó en principio una gran conmoción social y la oposición de la burocracia del partido, lo que le permitió a Nikita continuar con la "purga" de los herederos de Stalin y concentrar el poder, como lo había hecho en su tiempo el "padrecito Stalin" siguiendo la tradición política soviética, heredera de la tradición política rusa. En 1958 Jruschov era ya el jefe del Estado y del partido: el nuevo jefe de la burocracia política sustituía al líder carismático de una nación sacrificada en la guerra y vigilada y controlada por las redes de seguridad y partidarias totalitarias.

El 16 de junio de 1958 y tras ser procesado en un juicio secreto, el Presidente húngaro Imre Nagy 4 fue fusilado y su cuerpo enterrado en un

2 Nikita Jruschov, Informe Secreto al XX Congreso del PCUS, 25 de febrero de 1956. Versión online disponible en: http://www.marxists.org/espanol/khrushchev/1956/febrero25.htm

3 A partir de 1953, año en que murió Stalin, comenzó una paulatina campaña en contra del culto a su personalidad que él mismo había impulsado. Estrictamente el punto inicial de esta campaña de "desestalinización" comenzó con el discurso que dio Nikita Jrushov, Secretario General del Partido Comunista de la Unión Soviética, conocido como "Discurso secreto" o "Acerca del culto a la personalidad y sus consecuencias" dado el 25 de febrero de 1956, durante el XX Congreso del PCUS. Los momentos simbólicos más importantes de este proceso fue cuando se retiró el cuerpo de Stalin del Kremlin y cuando Stalingrado pasó a llamarse Volgogrado.Sobre el tema, véase: Hélène Carrère d'Encausse. 1956: La Déstalinisation commence. Bruselas: Éditions Complexe, 1984

4 Existe una biografía publicada recientemente: János M. Rainer. Imre Nagy: a biography. Londres-Nueva York: I.B. Tauris, 2009. Sobre la muerte de Nagy: véase http:/ / www.rev.hu/history_of_56/szerviz/kislex/biograf/nagy.htm 
lugar desconocido. Este político representante del comunismo humanista encabezaba el gobierno popular en el que culminaron los movimientos estudiantiles de 1956, revueltas de jóvenes que se convirtieron en movilizaciones sociales amplias en apoyo y en demanda de reformas de liberalización e independencia, fueron movimientos sociales nacionales surgidos en el entorno de la desestalinización.

La insurrección estudiantil en Budapest buscó la restauración de las libertades ciudadanas y políticas, el pluralismo político frente al monopartidismo, la libertad religiosa y la autonomía del gobierno frente a la hegemonía soviética buscando la neutralidad e independencia frente al Pacto de Varsovia que controlaba los estados nacionales del bloque a través de la red de partidos comunistas, la subordinación militar del Pacto de Varsovia y la centralidad soviética de las economías nacionales que establecía la división de producción económica en el bloque a través del Consejo de Ayuda Mutua Económica (COMECON), (Crouzet, 1961:731734; Procacci, 2001: 360-367). ${ }^{5}$

Esta es la primera vez en la historia del siglo XX que surgen las luchas estudiantiles en contra del orden de dominación político metropolitano del Estado soviético, la segunda, por las mismas razones y reprimida con los mismos métodos, sucederá doce años después, en 1968, en la Primavera de Praga con una Checoslovaquia movilizada que fue frenada por la invasión del ejército rojo que estaba ahí para preservar la hegemonía soviética frente a los países que formaban el bloque del cual era su metrópoli. La represión soviética en Hungría fue el punto de partida de la decepción y crítica de la intelectualidad de izquierda frente a la Unión Soviética, crítica que se ratificara con la Primavera de Praga.

Los años sesenta son inexplicables sin la guerra de Vietnam, a partir de la capitulación de las tropas francesas en mayo de 1954 después de la derrota militar en la Batalla de Dien Bien Phu frente al Viêt-Minh (Liga para la independencia de Vietnam). La liga estuvo dirigida por Nguyen Tat Thanh, más conocido como Ho Chi Minh, "El que Enseña", fundada en mayo de 1941 con el fin de conseguir la independencia de Francia. La guerra colonial en Vietnam tuvo una abierta oposición de la sociedad fran-

5 Para consultar sobre el movimiento estudiantil en Hungría véase: http://mek.oszk.hu/01200/01274/01274.pdf En esta liga se puede consultar el reporte del comité especial del problema de Hungría de las Naciones Unidas. Nueva York, 1957. 
cesa y la lucha por la independencia reclutó a miles de jóvenes - muchos casi niños - que se enrolaron en las filas guerrilleras. ${ }^{6}$

En 1955 después de la derrota militar francesa, el presidente Eisenhower, quien creía en la teoría del dominó, afirmó: “que si Vietnam del sur cae en manos de los comunistas, los otros países de la región sucumbirán uno después del otro" (Kaspi, 2002: 470). A partir de esta concepción estratégico-militar establece una política de intervención en el sudeste asiático que incluía Laos y Camboya y que concluye el 27 de abril de 1975 con la rendición de las tropas vietnamitas del sur y americanas, fecha en la que se pone fin a la guerra más larga de la historia moderna, 10,000 días a lo largo de más de 35 años. ${ }^{7}$

Durante los años que nos ocupan, esa guerra se convierte en el símbolo de las luchas juveniles por la libertad, el anticolonialismo y el anti-imperialismo. Por primera vez en la historia de los Estados Unidos estalla una fuerte revuelta anti-belicista en los jóvenes norteamericanos del Baby Boom quienes, ante el asombro colectivo, se niegan a salir de la nación para defender "la libertad y la democracia" y a enrolándose en las tropas que van a una guerra que aparece moralmente como injusta e intervencionista, llegando al extremo de quemar las tarjetas de reclutamiento militar e iniciando los distintos movimientos pacifistas que se agruparan bajo la nominación de hippies, movimientos pacifistas que se estacionan en los campus de las universidades de gran prestigio.

Las élites y los ciudadanos estadounidenses tenían el orgullo social de formar parte de la genealogía guerrera de la nación, identidad americana

6 Índice de noticias de la Guerra de Vietnam en el New York Times:

http://topics.nytimes.com/top/reference/timestopics/subjects/v/vietnam_war/index.html Especial de El Mundo sobre la Guerra de Vietnam

http://www.elmundo.es/internacional/vietnam/

Página de Texas Tech University: The Vietnam Project

http://www.vietnam.ttu.edu

Página con archivos de Ho Chi Min

http://www.marxists.org/reference/archive/ho-chi-minh/index.htm

Página de Facultad de Ciencias Sociales y Humanidades de la Universidad de Quebec y Montreal de la Guerra de Indochina

http://www.indochine.uqam.ca

Página con enlaces directos a documentos y páginas referentes a la Guerra de Vietnam

https://www.mtholyoke.edu/acad/intrel/vietnam.htm

7 La bibliografía sobre la guerra de Vietnam es muy vasta. Para un análisis de esta guerra y su efectos en la sociedad americana véase Todd Gitlin, 1993, The Sixties, Years of Hope, Days of Rage, New York, Bantam Books. Un texto que compila valiosas opiniones de importantes intelectuales de la época es Gerald Howard (ed.), 1991, The Sixties, St. Paul, Minnesota, Paragon House. 
que se construía y reproducía en la familia, institución básica que constituye el primer ámbito de la socialización (Simmel, 1977:16). El haber participado en las guerras que "dieron la grandeza a la nación más fuerte del mundo," después de la primera guerra mundial, era uno de los símbolos individuales de prestigio. Prestigio que compartían con sus ancestros, que en su momento fueron llamados a la guerra para construir y mantener la superioridad americana - primero en la conquista de su territorio y después en la hegemonía en el mundo - a la que los miembros de las familias norteamericanas habían contribuido y que en los años sesenta daba identidad y renombre, condición necesaria para participar en la cosa pública, como era el caso del joven presidente John F. Kennedy, héroe de la Segunda Guerra Mundial y quien en 1960 sustituye al general Dwight D. Eisenhower, vencedor de la misma guerra.

Este orgullo de guerrero americano era un valor moral con sanción social y un símbolo patriótico de identidad individual del buen ciudadano, que inició su agotamiento a mediados de la década de los sesenta. Muchos jóvenes universitarios que formaban parte de la élite se vuelven los contestatarios de una de las más importantes tradiciones liberales norteamericanas. (Jones, 1980). Hasta la guerra de Corea, y por primera vez en la historia americana, el haber participado en la guerra de Vietnam dejó de ser un orgullo y se volvió un estigma entre los jóvenes.

En los años sesenta el mundo sufre un vuelco y los inferiores y subordinados de las décadas anteriores se convierten en los actores centrales de la propuesta del cambio social y político: los jóvenes y los pueblos colonizados o periféricos, los llamados entonces "los negros y los de raza amarilla" escenificaron las nuevas revueltas por la libertad, en el interior o frente a las metrópolis del mundo occidental.

En esos años, el mundo paría lo nuevo y lo inédito abriendo el horizonte de los imaginarios colectivos a una nueva moral pública y privada que reemplazaba las medidas en el sistema de valores, con las que se juzgaban las conductas de los "diferentes". En esta década, el status de los inferiores pasa a ser el status de "los otros": de los diferentes pero iguales. Las relaciones sociales verticales de poder que dieron sentido a la autoridad y a la obediencia enraizando culturalmente el poder político, inician al final de los años cincuenta el camino de su reversión simbólica, cambio que desacredita las relaciones verticales e incuestionables volviéndolas, cada vez más, relaciones sociales horizontales y culturalmente correspondientes.

A mediados de los cincuenta aparecen representados en el ámbito de la cultura mediática de masas, los primeros signos de la nueva rebeldía juvenil que cubrirían crecientemente la segunda mitad de los años cincuenta 
y más allá de los sesenta. El cine, que es el espectáculo de masas más importante de la época, convierte al actor en celebridad y al artista en una de las figuras emblemáticas de la sociedad. Los actores y actrices aparecen ya como los verdaderos prototipos culturales, se vuelven los nuevos ídolos, "los símbolos" de la moda, de la elegancia, de la sexualidad y de la violencia. Sus figuras producen las imágenes que sostienen las modalidades del consumo masivo y dan forma a modalidades de identidad colectivas, sobre todo de ese nuevo nicho de mercado que son los jóvenes. El rostro de las celebridades, su cuerpo o su vestimenta, dan forma a las imágenes que sustenta la publicidad creciente en el mercado y construye el mensaje de la mercadotecnia - que en esa década se consolida - , estrategia publicitaria que pone al actor o a la actriz en el centro de la cultura de masas.

El 27 de octubre de 1955," se estrena la película "Rebelde sin Causa", protagonizada por James Dean de 24 años y dirigida por Nicholas Ray, en la que se escenifica la rebeldía juvenil y se construye su estereotipo social y cultural. La actuación convirtió a James Dean en uno de los ídolos juveniles, con millones de adolescentes como sus fanáticos. Esta condición de ídolo se transforma en mito al morir en un accidente automovilístico dos meses después de estrenada la película. Es la figura del rebelde sin causa la que pone en el centro de la moda adolescente la chamarra de cuero negro como el símbolo de identidad y de mayor consumo de la época, prenda de vestir a la que acompaña la gesticulación provocativa.

Una de las revoluciones culturales edificadas por los jóvenes y que es parte constitutiva de la Contracultura fue el cambio de actitud y el surgimiento de una nueva conducta social hacia la sexualidad. Este cambio aparece abiertamente en el espacio público mediático a la mitad de la década

8 El 9 de marzo de 1955 se estrena en los EUA “Al Este del Paraíso", película dirigida por Elia Kasan que tiene como actor principal al joven actor James Dean. En este film se caracteriza la distancia entre el puritanismo protestante paterno y el cinismo materno. Esta película fue un éxito de taquilla y produce una revolución en el cine. Para ver el tráiler de la película véase: http:/ / www.youtube.com/watch?v=cAlzg0S51GY 
de los cincuenta con el surgimiento de la nueva música, el Rock and Roll ${ }^{9}$ y su primer gran ícono, Elvis Aaron Presley, conocido como "el Rey del

Rock and Roll" o simplemente "el Rey". En 1956, aparece su primer sencillo Heartbreak Hotel, ${ }^{10}$ que se convirtió en el éxito número uno del hit parade. Tras sus apariciones en los medios, el rey se convirtió en la figura principal del popular sonido del rock, con una serie de presentaciones televisivas ${ }^{11}$ y éxitos que lo llevaron a la cima de las listas de ventas en el mundo. Elvis aparecía en público interpretando sus canciones y haciendo movimientos de cadera de carácter sexual y en abierta provocación a la moral puritana de los adultos de la clase media americana. ${ }^{12}$

Un cambio central en la interpretación musical es el remplazo de la Gran Orquesta de la década de los 40's y 50's por el cantante de rock y su banda, integrada por tres o cuatro músicos, agrupación musical cuyo nombre designa lo mismo a un grupo de jóvenes que tocan música que a un grupo de jóvenes que practican la violencia y en la década de los sesenta pueblan los barrios de las ciudades.

Las bandas adquieren su presencia en la cultura cinematográfica de masas con la película West Side Story (1961) (conocida como Amor sin barreras en Hispanoamérica), musical que narra la trama de dos pandillas callejeras en el Upper West Side, en Nueva York y que es la versión moderna de Romeo y Julieta. Esta película, novedosa por los bailes, obtiene el éxito

9 Se ha discutido extensamente acerca del origen del rock and roll, sin embargo la versión más difundida es que éste nació en Memphis, Tennessee, a mediados de los cincuenta. Sus rasgos esenciales en aquel tiempo eran el uso de un tempo rápido que mezclaba la música country, el rhythm y el blues. Este tipo de música fue con la cual Elvis Aaron Presley (1935-1977) se dio a conocer de la mano de Sam Phillips, propietario de la compañía musical Sun Records. Presley, junto con el guitarrista Scotty Moore y el contrabajista Bill Black difundieron estos sonidos novedosos familiarizados con la música afroamericana. Para una historia general del rock and roll véase: Robynn Stilwell, 2004, "Music of the youth revolution: rock through the 1960s", en Nicholas Cook y Anthony Pople (eds), The Cambridge History of Twentieth-Century Music, Cambridge, Cambridge University Press. Una vista previa al libro se puede encontrar en:

http:/ / books.google.com.mx/books?id=g3NweXtHo7wC\&printsec=frontcover\&hl=es\&sour

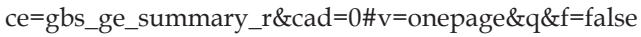

Para escuchar la canción Heartbreak Hotel: http:/ / www.youtube.com/watch?v=PotB76gi2_4

11 El 14 de enero de 1973 Elvis Presley dio el primer concierto que fue teletransmitido mundialmente vía satélite. Se habla de que éste fue visto aproximadamente por 1,500 millones de personas. El concierto de Elvis Presley "Aloha From Hawaii" puede ser visto en: http:/ /www. youtube.com/watch?v=ct4bFKwZJRo 
de la Academia en Hollywood, ${ }^{13}$ volviéndose un éxito de taquilla, al ser vista por millones de jóvenes y adolescentes en el mundo occidental. Su música fue escrita por el compositor americano de música clásica Leonard Bernstein y sus temas musicales vendieron millones de discos en el mundo.

En los sesenta, la producción cinematográfica y discográfica tuvo consumidores en todo el mundo y sus productos culturales masivos ejercieron influencia mundial. Esta década fue el inicio de la americanización cultural del mundo ligada al desarrollo de las estrategias del marketing de masas cuya teorización se inicia en la Harvard Business School por el economista Theodore Levitt, cuyos influyentes artículos ${ }^{14}$ aparecieron por primera vez en 1956 en la más importante revista de negocios del mundo: la Harvard Business Review.

Frente a la mirada educada por el deber ser de la tradición "burguesa" (el nombre es utilizado como adjetivo por los jóvenes y como estigma de las conductas de la generación adulta y no como categoría histórico analítica) los jóvenes sumergidos en la Contracultura "buscaban" la apertura de las percepciones sensoriales dadas por el consumo de estimulantes que rompieron las ataduras de la conciencia. Estas nuevas percepciones y estados sensoriales son acompañados por la nueva música que construye el ritmo experimental de la época psicodélica (psychedelia), que en la concepción de su creador, Humphry Osmond, la categoría manifiesta el alma. La droga masiva fue la mariguana y la droga psicodélica semi sintética por excelencia fue el LSD (ácido lisérgico) y sus efectos fueron conocidos como "viaje". Estos "viajes" producen estados alterados de conciencia equivalentes a la esquizofrenia que los hippies consideraban como experiencia mística.

13 West Side Story originalmente fue un musical en Broadway. Posteriormente en 1961 Robert Wise and Jerome Robbins dirigieron la versión cinematográfica con música de Leonard Bernstein. Entre los actores estaban Natalie Wood, Richard Beymer, Russ Tamblyn, Rita Moreno y George Chakiris. La película fue un éxito, obteniendo en 1961 once nominaciones de la academia y diez Premios Óscar incluyendo "Mejor Película" y "Mejor director", 3 Globos de Oro, y el premio del Círculo de Críticos de Nueva York a la mejor película. Video del prólogo de West Side Story en: http://www.youtube.com/watch?v=bxoC5Oyf_ss 
El consumo de drogas acompañó a la experimentación sonora - musical-que lleva al límite a la música rock en la composición Sgt. Pepper's Lonely Hearts Club Band que es el octavo álbum de estudio de la banda británica The Beatles aparecido el 26 de mayo de 1967..$^{15}$ Este álbum es considerado la culminación de la experimentación musical de los sesenta. La idea central del álbum es romper con las nociones de ritmo y secuencia musical y construir una nueva lógica de la composición y de la escucha. La nueva música conjuga orquestaciones, instrumentos hindúes, grabaciones tocadas al revés y sonidos de animales. Rock, Music Hall, Baladas, Jazz y hasta música oriental se mezclaron en la realización del álbum. La tercera canción del disco, Lucy in the Sky with Diamonds, fue la primera canción rock escrita en dos compases diferentes y es considerada como la primera composición psicodélica de la historia. Según Paul Mc.Cartney, integrante de los Beatles, la canción fue inspirada en los alucinógenos, como se puede ver en las iniciales de su título, con las cuales se forma la palabra LSD. ${ }^{16}$ Su difusión mundial y su consumo masivo hicieron que para la mayoría de jóvenes que participaron en los movimientos del 68 este disco fuera un referente obligado de su cultura.

\section{El cuerpo reencontrado. El reencuentro con el cuerpo}

La revolución sexual promovida por los jóvenes encontró en $1960^{17}$ el apoyo químico con aplicaciones médicas a su lucha por la libertad femenina. El 23 de junio de 1960, al ser aprobada para su comercialización en los Estados Unidos de América por la Administración de Alimentos y Medicamentos (FDA, por sus siglas en inglés), la píldora anticonceptiva se vendió de manera libre en el mercado. A lo largo de la década, la difusión de la píldora anticonceptiva fue mundial y cambió la vida de las mujeres diferenciado la sexualidad del determinismo biológico de la procreación que durante

15 http://www.thebeatles.com/\#/albums/Sgt_Peppers_Lonely_Hearts_Club. El álbum completo se puede escuchar en http:// www.youtube.com/watch?v=1T5fqLBhZgo

http://news.bbc.co.uk/2/hi/entertainment/3769511.stm

17 La píldora anticonceptiva apareció en el mercado de los Estados Unidos después de haber sido probada con las mujeres haitianas y puertorriqueñas. Para una breve historia de la píldora: http://news.bbc.co.uk/2/hi/health/250337.stm 
siglos dio sentido a las familias y sus linajes, maternidad sancionada por las religiones y custodiada por las iglesias y las familias. ${ }^{18}$

El uso de la píldora anticonceptiva se difundió por todo Occidente, pero fue bloqueado por los médicos soviéticos quienes la rechazaron, alabando las virtudes de los condones (conocidos coloquialmente como "galoshes"), el dispositivo intrauterino (DIU) y el diafragma. En 1968 el ministro de salud pública Boris Petrovsky declaró que la Unión Soviética se concentraría en un dispositivo de control de natalidad porque la píldora tenía "efectos secundarios negativos" (Kaser, 1976). ${ }^{19}$ Debido a la dificultad de hacerse de un control de natalidad fiable, el aborto, legalizado en 1955 se mantuvo, desde la guerra fría hasta los noventa, como el método anticonceptivo más extendido (J. Raleigh, 2012:144), con graves consecuencias entre las madres, principalmente jóvenes.

La actitud y el manejo de la sexualidad como parte integrante de la Contracultura y del inicio de los nuevos valores sociales que asientan un derecho individual y colectivo en contra de una concepción moral que estigmatiza la homosexualidad, se muestra en la primera manifestación abierta y lucha pública por ser diferente de la heterosexualidad dominante. A inicios de la década de 1960 el Alcalde de la ciudad de Nueva York, Robert F. Wagner, Jr., prepara a la ciudad para la Feria Mundial de Nueva York de 1964, iniciando una campaña mediante la cual buscaba erradicar los bares homosexuales de la ciudad. El 28 de junio de 1969, en el barrio de Greenwich Village, en Christopher Street, la policía organiza una redada en el bar gay, Stonewall Bar, que terminó en enfrentamientos y marchas de protesta contra la represión. ${ }^{20}$ Estas acciones colectivas que dieron origen

1850 años después de inventar la píldora anticonceptiva, Carl Djerass afirmó que no se ha inventado la contraparte para los hombres porque: "a las grandes compañías farmacéuticas no les interesa gastar los millones de dólares que costaría estudiar sus efectos secundarios". Asimismo, declaró que lamentaba este hecho ya que la responsabilidad reproductiva seguía recayendo sobre las mujeres. El País 20 Junio de 2013. versión en línea:

http://sociedad.elpais.com/sociedad/2013/06/20/actualidad/1371753378_785942.html

Boris Petrovsky, Ministro de Salud Pública de la Unión Soviética a finales de 1968 declaró que la píldora tenía efectos secundarios negativos por lo que la URSS manufacturaría un millón de bucles intrauterinos y abriría seminarios para enseñar a las mujeres cómo usarlos. La declaración se encuentra en Sarasota Journal del 12 de diciembre de 1968.

20 El 28 de julio, día de la redada policial en el bar gay Stonewall, es la fecha mundial en la que se llevan a cabo las marchas en el mundo por el orgullo gay. Esta marcha se inició al año siguiente de la represión, 1970 en Nueva York. Fotos de la primera marcha por el orgullo gay (fuente indirecta: New York Public Library archives).

http://www.brainpickings.org/index.php/2013/06/28/vintage-pride-parade/ 
a un nuevo movimiento social, que se nombró, como se nombraba en la época a lo nuevo, con el adjetivo: power; de poder, como black power (poder negro) y en este caso el poder gay (gay power).

El barrio de Greenwich Village se había vuelto, al final de la primera guerra mundial, el espacio urbano de la subcultura gay. En este barrio habitaban importantes representantes de la cultura intelectual y artística de la ruptura, como el poeta americano Allen Ginsberg quien fuera el enlace entre el movimiento beat de los años cincuenta y los hippies de los años sesenta y cuyo censurado poema Howl (Aullido), ${ }^{21}$ marca un punto de inflexión en la posvanguardia. Este personaje afirmó:

“¡Poder gay! ¿No es genial? Somos una de las más grandes minorías en el país, $10 \%$ como tú sabes. Era tiempo de que hiciéramos algo para reafirmarnos. [...] Los chicos allí estaban tan guapos, habían perdido esa mirada herida que todos los maricones tenían hace diez años".22

Un año después de la represión, el 28 de junio de 1970 se celebró el primer aniversario de los disturbios con la primera marcha del orgullo gay de la historia. La marcha partió del bar Stonewall y recorrió 51 manzanas hasta llegar a Central Park. ${ }^{23}$ La fecha quedó fijada en la representación colectiva, primero en los EUA y después en el mundo entero como la fecha del Orgullo Gay y la manifestación con la que este orgullo se demuestra. En Nueva York la marcha sigue iniciando en Stonewall, mientras que en

21 Para escuchar a Ginsberg leyendo "Howl" véase: http://www.youtube.com/ watch?v=MVGoY9gom50

22 Lucian Truscott, "Gay Power Comes to Sheridan Square", The Village Voice, Julio 3 1969. p. 1-18, (traducción propia)

23 The New York Times cubrió la primera Marcha del Orgullo Gay con una nota de Lacey Fosburgh el 29 junio de 1970 cuyo encabezado decía: "Miles de homosexuales realizan una manifestación de protesta en el Central Park". El inicio de la nota es revelador: "Miles de hombres y mujeres jóvenes homosexuales de todo el noreste marcharon de Greenwich Village a Sheep Meadow en el Central Park ayer, proclamando "la nueva fuerza y orgullo de la gente gay". Lacey Fosburgh. "Thousands of Homosexuals Hold A Protest Rally in Central Park", The New York Times, 29 Junio 1970. 
el caso de la URSS la homosexualidad estuvo prohibida legalmente y sancionada con la cárcel durante sesenta años, desde 1933 hasta 1993. ${ }^{24}$

Las luchas de los sesenta abrieron los espacios culturales y a lo largo de la segunda mitad del siglo XX, la Contracultura se fue desagregando en subculturas particulares que fueron el resultado de las confrontaciones y movilizaciones juveniles en contra de la censura general, fundada en la moral puritana.

En la sociedad de los sesenta se inició el proceso de cambio cultural hacia el cuerpo humano, revolución sensual promovida por los jóvenes que tuvieron un cuerpo distinto al de sus padres formados en la rígida disciplina corporal de la cultura judeo-cristiana del pecado, con su representación del cuerpo como el objeto del mal (del pecado judío cristiano) y el límite y cárcel del alma. Los jóvenes de los sesenta revolucionaron el cuerpo, volviéndolo uno de los ámbitos de la vida más ricos y diversos del conocimiento humano.

Como parte de las batallas culturales por la creación de nuevos valores de conducta pública y las prácticas y derechos privados, aparece en el escenario social la Segunda Ola del Feminismo fechada el año mismo en el que se inicia la década: 1960, y que se extiende más allá de los años ochenta. ${ }^{25}$

Para 1960, las mujeres habían ganado ya - no de manera homogénea para todas las razas, los grupos étnicos y la minorías, ni en todas las sociedades, ni reconocido como derecho por todos los regímenes legales de los Estados Nacionales - las batallas legales que contenían el derecho a la propiedad, a la herencia, a la igualdad política, al sufragismo: a votar y a

24 Bajo el artículo 121 del Código Penal de la URSS, el cual se promulgó en 1933, las relaciones sexuales consensuadas entre hombres estaban penadas con hasta cinco años de prisión (Artículo 121.1). Esta pena aumentaba a ocho años si las relaciones se habían dado utilizando la fuerza o si involucraban a un menor de edad (Artículo 121.2). En el caso del lesbianismo no se explicitaba ninguna sanción. El articulo 121 sección 1 (relaciones entre hombres consensuadas) fue abolido el 29 de abril de 1993 por un decreto firmado por el presidente Boris Yeltsin. El artículo 121.2 (relativo al uso de violencia y a los menores de edad) se mantuvo. "The Criminal Code of the USSR", en William Elliott Butler (compliador, traductor y editor), Basic Documents of the Soviet Legal System, Nueva York, Oceana Publications, 1992.

Para la Segunda Ola del Feminismo véase: Jane F. Gerhard, 2001, Desiring revolution: secondwave feminism and the rewriting of American sexual thought, 1920 to 1982, New York, Columbia University Press; Nancy Cott, 1987, The grounding of modern feminism, New haven, Yale University Press; Barbara Ryan, 1992, Feminism and the Women's Movement: Dynamics of Change in Social Movement Ideology and Activism, New York, Routledge, 1992; Becky Thompson, 2012, "Multiracial Feminism: Recasting the Chronology of Second Wave Feminism", Feminist Studies, 28, núm. 2; Benita Roth, 2004, Separate roads to feminism: Black, Chicana, and White feminist movements in America's second wave, Cambridge, Cambridge University Press. 
ser votadas, derecho político que abrió la posibilidad del desempeño en cargos institucionales, tanto en los gobiernos como en los de representación civiles y laborales, al trabajo legalmente reconocido y protegido en su condición de trabajo femenino. La lucha por estas demandas dio forma a la llamada Primer Ola del Feminismo, cuyo origen está en las mujeres y sus ancestrales batallas por su individualización y que las especialistas no llegan a fechar. En el caso de la Segunda Ola del Feminismo las teóricas están de acuerdo, en que 1960 fue el punto de partida. Las demandas de las mujeres avanzaron - en sintonía con las otras luchas sociales y políticas expandidas en la década de los sesenta - hacia los derechos sexuales y reproductivos, en los que la maternidad se constituye como un acto de conciencia y voluntad individual. Junto con la revolución en los derechos privados, el feminismo de los sesenta luchó por un derecho igualitario en el trabajo y en la familia. ${ }^{26}$ Es en esta segunda ola feminista que se construye la categoría de "género".

La categoría de género es establecida por primera vez en 1955 por el sicólogo y sexólogo John William Money quien estableció la diferencia entre sexualidad, identidad de género y roles de género (gender roles) para describir el conjunto de conductas atribuidas a los hombres y a las mujeres. Hacia el final de la década, en 1968, el psiquiatra Robert Stoller fija los términos de la diferencia entre "sexo" y "género", siendo el sexo determinado por la diferencia fijada en el cuerpo, y el género por los significados que cada cultura le atribuye a las funciones sociales de lo masculino y lo femenino. ${ }^{27}$ Desde finales de los sesenta las instituciones educativas y las organizaciones sociales explicarán las diferencias en la relación social entre hombres y mujeres a través de esta categoría.

En esos años sesenta, el cuerpo femenino se resensualiza masivamente, primero en Londres y después en las otras capitales del mundo - había habido tiempos en donde las vanguardias feministas enarbolaron la libertad sexual - y se despoja de lo que lo oculta, de lo que lo cubre como el objeto del deseo y mostrarlo deja de ser un acto de vergüenza frente a los prejuicios públicos. La revolución en la percepción del cuerpo fue absorbida

26 El libro clásico sobre el feminismo, leído en extenso por los jóvenes de los años sesenta fue escrito por Simone de Beauvoir, "El segundo sexo", texto escrito entre 1948 y 1949. El libro tiene cientos de ediciones y traducciones. En inglés el libro aparece en 1953 The Second Sex, Vintage Books.

27 Véase el trabajo clásico de Robert, Stoller, 1968, Sex and Gender: On the Development of Masculinity and Femininity, New York, Science House. 
por el mercado y volvió a la provocación tendencia de la moda, subiendo la falda veinte centímetros por arriba de la rodilla. Según la diseñadora Mary Quant, - quien reclama junto con el francés André Courrèges, la invención de la minifalda, presentada en el desfile de modas del invierno de 1965 en París - , las mujeres debían mostrar las rodillas pues son una de las partes más sensuales del cuerpo femenino. La minifalda se volverá la prenda más usada por las mujeres jóvenes de los sesenta.

La minifalda tuvo como equivalente en el traje de baño al bikini, inventado por Louis Reard y mostrado al público parisino el 5 de julio de 1946 en la Piscine Molitor, una popular alberca en París. El traje de baño tuvo que ser mostrado por Micheline Bernardini, bailarina nudista del Casino de Paris, ya que ninguna modelo profesional aceptó ponérselo. ${ }^{28}$ El bikini adquirió popularidad y fue masivamente usado a principios de los años sesenta, convirtiéndose en un escándalo para la sociedad de esa época puesto que dejaba ver primero, las piernas de las mujeres, el abdomen y parte de los senos, y posteriormente el ombligo.

El bikini abrió el debate sobre el cuerpo de la mujer y las formas de la desnudez. En muchas playas de Estados Unidos y Europa se prohibió su uso, bajo amenaza de arresto. Pero también tuvo sus seguidoras, una de ellas fue la actriz Brigitte Bardot, quien además de posar en sesiones fotográficas con este atuendo, en 1956, popularizó su uso en la película 'Y Dios creó a la mujer', ${ }^{29}$ dirigida por su marido, Roger Vadim. La actriz se volvió un de los símbolos sexuales a nivel internacional compartiendo la fama de la sensualidad mundial con Marilyn Monroe, símbolos que forman parte del mercado cinematográfico y su marketing. Pero la exhibición del cuerpo femenino no acabó ahí. En 1964 apareció en el mundo de la moda el "monokini" o "topless swimsuit", con el que se dejaba al descubierto los senos de las mujeres. ${ }^{30}$

La sensualidad del cuerpo femenino no sólo se manifestó en el ámbito de lo público, sino que se trasladó a la ropa interior, a lo privado y fue la invención de las panties, la prenda femenina más sexy - como se anunciaba y exhibía en los maniquíes en las tiendas departamentales - la que

28 "Micheline Bernardini Models the First-Ever Bikini", Time , 5 de julio de 2011

29 Un tráiler de la película se puede ver en: http:// www.youtube.com/watch?v=Kmqv88jWhyE

30 Véase el texto editado por Jim Heiman, 2007, 60s Fashion, New York, Taschen. Este texto es una compilación de fotografías de todos productos de la moda de los años sesenta con artículos de críticos de moda especializados en la época. 
revistió a las mujeres con una nueva ropa íntima, sensual y liberadora, confrontando con su uso el peso de los mitos y prejuicios que caían sobre la pareja y que imponían el mandato de la sexualidad fría y reproductiva como la conducta aceptable de la esposa y con la esposa. Esta nueva prenda desplazó a los austeros calzones de las décadas anteriores.

La expresión correspondiente de la liberación sexual femenina en el mundo público se expresó en el cambio de las conductas privadas y en la transformación de las actitudes en la intimidad. Este cambio de actitud, libre y abierta, se dio en el interior de una de las tres instituciones que forma la base de la sociedad: la familia y la relación en la pareja que la forma, institución sustentada en una cultura del matrimonio presidida por los dogmas que cercaban al cuerpo femenino con los mitos del deber ser, estigmatizando su libertad sexual y anulando su posibilidad seductora. Lo nuevo en la cultura de masas, promovido por la publicidad y orientado por el marketing, fue una mirada distinta hacia lo femenino, que consideraba natural exponer el cuerpo para revestirlo culturalmente de nuevos atractivos que reafirmaban la sensualidad que estimula la sexualidad. El derecho de las mujeres a la realización sexual fue la transformación en la conducta privada de la revolución pública feminista. Este derecho, que antes de los sesenta fue la lucha de una vanguardia, se irá estableciendo como parte de la llamada Segunda Ola del Feminismo, a lo largo de las décadas siguientes, hasta quedar asentado como parte de la vida cotidiana.

\section{La Contracultura}

Los distintos procesos particulares iniciados por la masa de jóvenes como actos de rebeldía en contra de los valores del statu quo motivaron conductas individuales, de grupo y acciones colectivas que van constituyendo, a lo largo de la década de los sesenta, lo que se conceptualizó como Contracultura. La cual fue caracterizada por Theodore Roszak, uno de sus más importantes analistas y teóricos, en los siguientes términos:

Se cuestionaba todo: la familia, el trabajo, la enseñanza, el éxito, la educación de los hijos, las relaciones entre hombre y mujer, la sexualidad, el urbanismo, la ciencia, la tecnología, el progreso. Los medios de la riqueza. El significado del amor, de la vida, todo necesita someterse a evaluación ¿Qué es la cultura? ¿Quién decide lo que es excelencia? ¿Y conocimiento o razón? (Roszak, 1995: XXVI).

Las conductas sociales de la Contracultura estaban totalmente asimiladas por los jóvenes en 1968, en donde los procesos sociales y las luchas 
culturales adquieren un significado político y se vuelven el primer gran movimiento social de carácter internacional con correspondencias nacionales, pero con una sincronía que muestra el final de un tiempo social y político construido durante la segunda postguerra.

El cambio social y cultural edificado durante los sesenta obligará a los gobernantes de las tres décadas posteriores, a rehacer el andamiaje legal y a rediseñar las instituciones civiles y estatales que regulan la vida social cotidiana, para acreditar a los gobiernos frente a una sociedad que cambió y que se expresó políticamente en la convergencia de los movimientos de 1968. A finales de los sesenta, los políticos que fundaron su prestigio en el triunfo de la II Guerra habían sido desplazados. En los EUA el prestigio del presidente Dwight David "Ike" Eisenhower no pudo validar a su Delfín, el vice presidente Richard Nixon frente a John F. Kennedy, en una elección muy controvertida.

El caso paradigmático del agotamiento generacional de los contenidos simbólicos que acreditan el poder político en el ejercicio del gobierno, representados por un político de prestigio mundial fue el de Charles De Gaulle, héroe de la liberación; fundador de la quinta República; enfrentado a los militares y a los grupos colonialistas en Argel, a la que concedió la independencia en 1962 (acción que marcó los movimientos anticoloniales en África); único dirigente mundial que confrontó a los EUA en contra de la hegemonía del dólar como moneda mundial y referente único de cambio y equivalente general del patrón oro; quien sacó a Francia de la OTAN y promovió la conciliación franco alemana entre otras cosas importantes. ${ }^{31}$

Charles De Gaulle, hombre de Estado y único sobreviviente de los cuatro grandes de la segunda guerra mundial, tuvo el talento político de ver el significado profundo de "mayo de 1968", junto con los otros movimientos estudiantiles en el mundo, movimientos que expresaban la presencia de una sociedad joven, diferente y distinta a aquella en la cual, la eficiencia de los símbolos de prestigio de su autoridad política, que convocaron a la sociedad francesa junto con los instrumentos institucionales forjados en la pos guerra y reiterados durante 20 años, eran el pasado y no formaban más parte del referente cultural, ni de la memoria colectiva de la mayoría joven y en ascenso de la sociedad de los sesenta. Realidad social frente a la cual De Gaulle convoca a un referéndum nacional sobre la reorganiza-

31 Sobre la vida de Charles De Gaulle, véase: Charles de Gaulle, 2000, Mémoires, París, Gallimard; André Malraux 1976, Le Miroir des Limbes. París, Gallimard; Alain Peyrefitte, 2002, C'était de Gaulle: París, Gallimard. 
ción regional y del Senado, en abril de 1969, mismo que pierde y lo lleva a dimitir el 28 de abril de 1969.

Los movimientos estudiantiles de 1968 son el punto de llegada de una década de cambios sociales que tienen múltiples contenidos culturales, procesos surgidos de la contestación y la crítica a las convenciones sociales establecidas, que van configurando, a través de luchas específicas emprendidas por actores sociales particulares, los diversos contenidos de la Contracultura.

Estos movimientos estudiantiles fueron paralelos en el mundo y condensaron, un conjunto de acciones colectivas que confrontaron las normas morales vigentes, resguardadas por leyes y custodiadas por reglamentos particulares y locales. Las protestas de jóvenes se alzaron en contra de los prejuicios sociales y políticos sustentados en lo que en esos años se llamaban las "buenas costumbres." Estos movimientos sociales culminan las múltiples batallas y sus triunfos particulares en los distintos ámbitos específicos de la vida social y frente a las formas culturales e institucionales vigentes. Con esta cauda de protestas vitales y de cambios particulares la década confluye en 1968, año que fue tiempo de llegada, pero también punto de partida: el inicio de la otra historia el siglo XX.

La lucha por la palabra, la primera batalla por la nueva libertad

Los movimientos estudiantiles de 1968 tienen raíces históricas nacionales pero son también procesos mundialmente compartidos, diversidad que conjuga diferentes características específicas, tanto de las regiones del mundo como de la geopolítica en la que éste se dividía durante la Guerra Fría. En principio, las luchas estudiantiles fueron la expresión de un cambio en la estructura social dado por la expansión del sector servicios de la economía y la ampliación de los sectores medios urbanos, ampliación a la que pertenecían los jóvenes urbanos que protagonizaron los nuevos movimientos sociales, caracterizados así por la sociología de su tiempo. Esta caracterización sociológica establecía un claro contraste con las múltiples versiones de los marxismos sobre la estructura social y el sentido transformador de la clase obrera industrial y el movimiento obrero, al que se le adscribía la centralidad del cambio social y la condición "revolucionaria" de la lucha política de la sociedad, en la cual su lucha por la liberación era la liberación del conjunto de clases dominadas.

En la representación colectiva de los sesenta, los estudiantes eran los beneficiarios masivos del crecimiento económico y el desarrollo social que 
caracterizó a las sociedades occidentales en expansión entre 1955 y 1973. En estas dos décadas doradas, los universitarios fueron los beneficiarios del desarrollo económico y de las grandes oportunidades en el campo educativo promovido por el Estado Social, promesa del bienestar cuidado por las generaciones de la guerra que ejercían las funciones institucionales de la época. Paradójicamente, los consentidos del mundo irrumpen en el escenario público de los años sesenta como los críticos del statu quo del que eran los beneficiarios y aparecen como los nuevos sujetos sociales que promueven el cambio social: los más educados de la sociedad se volvieron los promotores de la nueva revolución cultural que rompía generacionalmente la continuidad de sus ventajas.

Una de las raíces del cambio, que aflora como la existencia de una masa de jóvenes que irrumpe en los años sesenta y se condensa en los movimientos de 1968, la constituye el fenómeno demográfico caracterizado como Baby Boom (explosión de la natalidad), ciclo demográfico comprendido entre 1946 -1964..$^{32}$ Esta explosión de la natalidad fue un fenómeno histórico cultural dado por el regreso de los hombres de la guerra a la pareja, y constituye un proceso social que da origen a una nueva cultura familiar, construida al final de la Segunda Guerra Mundial. Este fenómeno específico se inserta en la tendencia general de la transición demográfica, transición que fue el efecto del incremento de la población mundial y la disminución de la mortalidad infantil.

El Baby Boom no sólo fue el resultado del cambio en las políticas públicas del Estado Social de la posguerra, con la expansión de la medicina social, el mejoramiento de las condiciones de salubridad, de la dieta alimentaria, la calidad de vida y la movilidad social ascendente de una parte importante de la población, así como de la ampliación del consumo, sino también fue un fenómeno cultural que tuvo como contenido simbólico una reacción vital generalizada frente al fenómeno colectivo de la guerra mundial,

32 Se denomina "baby boomers" a las personas nacidas entre 1946 y 1964, periodo en el que se dio una explosión de nacimientos ("baby boom") en varios países y que está caracterizado por el incremento en las tasas de natalidad. En el caso estadounidense, se ha divido a los "baby boomers" en dos segmentos generacionales. Por un lado, aquellos que nacieron entre 1946 y 1955. Por el otro, los que nacieron entre 1956 y 1964. Para los primeros, las experiencias generacionales que los envuelven son la guerra de Vietnam, el asesinato de John F. Kennedy y Martin Luther King Jr., el movimiento hippie; para los segundos, el Watergate y la crisis del petróleo (1973). Sobre el tema, véase: Landon, Jones, 1981, Great expectations: America and the baby boom generation, New York, Ballantine Books. Para un estudio acerca de qué causó el fenómeno de los "baby boomers" véase: Greenwood, Jeremy, Ananth Seshadri y Guillaume Vandenbroucke, 2005, "The Baby Boom and Baby Bust", The American Economic Review, vol. 95, no. 1. 
experiencia masiva de la muerte y sus horrores. Esta reacción en cadena creó, en la paz amenazada por la bomba atómica y el equilibrio del terror de la Guerra Fría, una nueva psicología social dirigida al cuidado de estas dos generaciones de niños que fueron objeto de atenciones no existentes en las generaciones anteriores sometidas a la severidad familiar y a la violencia de la educación.

Los Baby Boomers fueron cobijados por la flexibilización de los padres, revolución psicológico-social en los cuidados de los niños y contenida en el libro paradigmático del Dr. Benjamin McLane Spock: El libro del sentido común del cuidado de bebés y niños (The Common Sense Book of Baby and Child Care) ${ }^{33}$ publicado en 1946, texto que se volvió uno de los mayores best-sellers de todos los tiempos, con 50 millones de ejemplares vendidos hasta 1998 y traducido a 42 lenguas distintas. ${ }^{34}$ El libro aparece en el mercado americano en 1946 - el mismo año en el que los demógrafos fechan el inicio del fenómeno de la explosión de la natalidad e inicia, en todo el mundo occidental, el canon de las publicaciones masivas y difusión sobre los múltiples cuidados de los niños y las responsabilidades de los padres. Actitud colectiva que se expresa en el retorno de Sigmund Freud y las múltiples escuelas psicoanalíticas y la divulgación masiva de las psicologías, que convergen en la máxima edificada por el lugar común de "infancia es destino".

El Dr. Spock postuló la tolerancia y el cuidado afectuoso de los hijos confrontando la rígida tradición de la disciplina en la que fueron educados los padres. Los jóvenes contestatarios del sesenta y ocho fueron también individuos formados en la cultura de los nuevos valores sobre la infancia que sustenta el derecho a su condición individual.

Pero los baby boomers que de jóvenes revolvieron la vida pública de las sociedades urbanas ejerciendo todos los derechos políticos, son también

33 Benjamin Spock, The Common Sense Book of Baby and Child Care, fue publicado por primera vez en Estados Unidos en 1946. Para consultar la obra del Dr. Spock véase: http:// books.google.com.mx/books/about/The_Common_Sense_Book_of_Baby_and_Child. html?id=AEk0AAAAIAAJ\&redir_esc $=y$

34 Pace, Erick, 1998, “Obituary: Benjamin Spock, World's Pediatrician, Dies at 94, en The New York Times, 17 de marzo, version online:

http://www.nytimes.com/learning/general/onthisday/bday/0502.html 
producto de la revolución en la educación, introducida por John Dewy ${ }^{35}$ en la posguerra. Para el creador de la filosofía progresiva, el niño debe ser educado para buscar, inquirir, explorar y sumergirse en el entorno colectivo y aprender de la experiencia. Esto llevaría a un crecimiento (forma más deseable de comportamiento humano) y crearía en el educando la disposición de reaccionar siempre a las nuevas situaciones con interés, flexibilidad y curiosidad.

La influencia de un libro va mucho más allá de sus lectores directos. Los postulados contenidos en su textualidad son difundidos, parafraseados y deformados en la divulgación realizada por los órganos de difusión masiva: revistas, programas de radio y de televisión, así como en el trato directo con los padres, en conferencias, pláticas, etc. Estos dos autores se convirtieron en la décadas de los cincuenta y los sesenta - período de la educación de los Baby Bommers - en el referente textual de los padres y maestros formadores de los jóvenes que ejercieron desde mediados de los sesenta la libertad de cuestionarlo todo.

Estas obras son el canon, el referente textual que se vuelve principio de autoridad de la cultura de un tiempo, obras que sin haber sido leídas por los miembros de una sociedad son citadas como referente de autoridad en la argumentación cotidiana que valida un conjunto de actitudes y valores que soportan, tanto la administración ejercida por los funcionarios al frente de las instituciones: escuelas, iglesias, hospitales, como las conductas privadas individuales en el seno de las familias.

La masa de jóvenes urbanos, convertida en el nuevo actor político, marcó su presencia modernizadora en el escenario público, construyendo una nueva centralidad crítica que edificó la contestación como una nueva experiencia de la modernidad, como una nueva escritura en la historia. "La condición auto fundadora de la modernidad implica su superación perpetua, es decir, ésta se refunda "cada vez que se presenta una escritura distinta de la historia" (Meshonnic, 1988:28) en la cual el pasado y el fu-

35 John Dewey (1859-1952), considerado el padre de la psicología progresiva, sostuvo la tesis de que la educación tenía como una de sus funciones esenciales ser instrumental para contribuir a la supervivencia de la sociedad. El alumno debía ser educado para que por sí mismo pudiera insertarse en su entorno y aprender de las experiencias, además, debía aprender a tener la capacidad de responder positivamente a nuevas situaciones. Véase, Dewey, John 1916, Democracia y educación, una introducción a la filosofía de la educación, Massachusetts, The Macmillan Company. Para ahondar en el tema véase: Westbrook, Robert B. 1993, "John Dewey" en Perspectivas: Revista Trimestral de Educación Comparada, París, UNESCO: Oficina Internacional de Educación, vol. XXIII, nos 1-2, pp. 289-305. Versión online:

http://www.ibe.unesco.org/publications/ThinkersPdf/deweys.pdf 
turo se ordenan conforme a los contenidos ideológicos dominantes en la concepción de un presente que se vuelve la representación colectiva del tiempo renovado (Pozas, 2006:45).

La crítica intelectual de los jóvenes universitarios confrontó las ideologías cerradas y agotadas desde los años cincuenta, ideologías sobre la educación superior constituidas como "sistemas intelectuales que reclamaban la verdad para sus concepciones del mundo" (Bell, 1988:19). La primera de las críticas fue al sistema universitario heredado de la posguerra hasta la década de los sesenta, sistema vertical, elitista, excluyente, en el que pedagógicamente y culturalmente se socializaba a los estudiantes en un sistema profesoral.

Los estudiantes se vuelven el actor social que emerge de lo privado a lo público, de la casa a la calle, del sistema de educación básica y media a la universidad y de la universidad a la batalla por la universalidad de los nuevos valores de la tolerancia que dan contenido a la libertad, del campus y la universidad a la sociedad y a la defensa de una nueva individualidad que confronta la ciudadanía tradicional fundada en los nacionalismos que estaban en la base del Estado moderno que la segunda guerra confirmó.

La lucha por la nueva libertad edificó su utopía y su icono, figura que en gran parte del mundo fue el Che Guevara, guerrillero muerto en Bolivia, en La Higuera, el 9 de octubre de 1967 por el ejército boliviano. El Che tuvo que salir de una Cuba cada vez más totalitaria, reproductora del modelo soviético de las funciones del Estado y del partido comunista en la sociedad, de una Cuba encuadrada en la lógica de la Guerra Fría que quedó subordinada en el ajedrez político global, como lo prueba su exclusión de las negociaciones entre Kennedy y Jruschov durante la crisis de los misiles en octubre de $1962 .{ }^{36}$

El Che encarnó el sentido de la libertad que recorría y unía el lado joven del primero y del tercer mundo, nulificando sus diferencias y construyendo su identidad en torno a la utopía de un futuro libre y justo. El joven guerrero muerto por la dictadura boliviana en 1967 fue, para los jóvenes estudiantes del 68, la imagen del héroe que confronta el orden establecido y encarna la utopía, el espíritu romántico libertario y como tal, la nueva

36 Véase el trabajo de Johnson, Paul, 1983, A History of the Modern World, London, George Weidenfeld \& Nicolson Ltd, pp. 216-229. Un texto importante sobre el tema es el escrito por el hermano del presidente norteamericano y Procurador General, Robert F. Kennedy, Thirteen days: A Memoire of the Cuban Missile Crisis.

http://books.google.com.mx/books/about/Thirteen_days.html?id=SCheG_TBySkC\&redir_ $\mathrm{esc}=\mathrm{y}$ 
moral pública que sustenta los juicios de los jóvenes en sus acciones colectivas: el Che fue quien afirmó: "defiendo a la revolución como moral", construyendo la condición revolucionaria como principio ético de sacrificio - con toda la densidad simbólica que tiene éste en la tradición judeocristiana de Occidente - y con ella se reinstaura la nueva moral pública de la lucha por la justicia y la nueva libertad.

El Che trajo de nuevo la utopía frente al utilitarismo político-burocrático en el que habían quedado atrapadas las direcciones políticas cubanas y que internacionalmente se expresaba en el nuevo equilibrio externo de la llamada Coexistencia Pacífica, como la nueva etapa de la Guerra Fría. En el 68 no hubo movimiento estudiantil en el que no ondeara su imagen, su cara fijada en el tiempo a sus 31 años de edad por el fotógrafo Alberto Díaz (Korda). ${ }^{37}$ No se realizó marcha en los movimientos estudiantiles y discurso juvenil que no repitiera lo que él dijo: "Crear dos, tres...muchos Viet-Nam, es la consigna". ${ }^{38}$

\section{El estallido}

La década joven de los sesenta mostró su fuerza transformadora frente a la intolerancia rígida y conservadora del ejercicio de la autoridad en todos los órdenes de la vida social, vigente en las instituciones universitarias, constituidas culturalmente por formas autoritarias en donde la enseñanza fue también una instrucción del deber ser y en el que la educación era también un entrenamiento para el éxito en el que se ejercitaba el carácter, se introyectaban los valores dominantes como el universo de representaciones del deber ser adulto y ciudadano. La universidad de los cincuenta era el espacio institucional en el que se socializaban a los jóvenes en las profesiones y en las conductas posibles en el mercado laboral y en los campos social y político.

37 Para ver algunas de las fotografías de Korda véase: http:// profesor-daniel-alberto-chiarenza. blogspot.mx/2012/05/25-de-mayo-de-2001-fallecimiento-en.html

38 Consigna que aludía a un texto del "Che" Guevara publicado el 16 de abril de 1967 en un Suplemento Especial de la revista Tricontinental: “¡Cómo podríamos mirar el futuro de luminoso y cercano, si dos, tres, muchos Viet-Nam florecieran en la superficie del globo, con su cuota de muerte y sus tragedias inmensas, con su heroísmo cotidiano, con sus golpes repetidos al imperialismo, con la obligación que entraña para éste de dispersar sus fuerzas, bajo el embate del odio creciente de los pueblos del mundo!" Para consultar el texto completo véase: http://www.filosofia.org/hem/dep/cri/ri12094.htm 
Los movimientos estudiantiles contestatarios al statu quo y liberta--rios arrancan con el Free Speech Movement (FSM), movimiento estudiantil iniciado el 1 de octubre de 1964 en el campus de la Universidad de Berkeley, en California, en el cual los estudiantes protestan en contra de la prohibición impuesta por las autoridades para realizar actividades políticas dentro del campus y luchan por el reconocimiento de su libertad de expresión política y académica.

Los movimientos estudiantiles detonan en 1968 en América, Asia, Europa y Medio Oriente. Estos movimientos tienen elementos que pueden ser considerados comunes en el mundo frente a las diferencias de las sociedades nacionales en los que éstos tuvieron lugar, marcando elementos de diferenciación entre ellos, no sólo por sus demandas particulares, sino también en los tipos de lucha y finalmente en la manera en que dichos movimientos sociales son enfrentados y "resueltos" por cada uno de los gobiernos de los Estados Nacionales. Aunque es precisamente la sincronía, por encima de las diferencias del desarrollo económico y las tradiciones políticas y sociales lo que marca su identidad y da sentido al año de 1968, tiempo fijado en la historia con un número del calendario, fecha que contiene para historia del siglo $\mathrm{XX}$ una densidad y un significado asociado a la juventud, al cambio cultural, a la libertad, a la desobediencia de las formas y a la innovación en los signos y los lenguajes.

En las sociedades post-industriales - para utilizar la nomenclatura de la época - en el año de 1968 tuvieron lugar movimientos estudiantiles en: Estados Unidos, Francia, Alemania e Italia; en la otra Europa, la mediterránea, en España; en Asia, en Japón, en los países latinoamericanos: en Argentina, Bolivia, Brasil, Perú, Uruguay ${ }^{39}$ y México, ${ }^{40}$ en Medio Oriente en Turquía. Un elemento constante de los movimientos estudiantiles en esta parte del mundo fue el anti-belicismo y el anti- intervencionismo nor-

39 Para los movimientos estudiantiles en América Latina véase: Guillermo Boils Morales, Loyo Brambila Aurora y Pozas Horcasitas Ricardo, Cronología de la Violencia Política en América Latina (1945-1970), op. cit. pp.551-573; González Marín, Silvia, Ana María Sánchez Saenz (coords), 2011, 154 años de movimientos estudiantiles en Iberoamérica, México, Universidad Nacional Autónoma de México.

40 Para el 68 mexicano véase Ramírez, Ramón, 1969, El movimiento estudiantil de México, Julio-diciembre de 1968, México, Editorial Era, 2 volúmenes; Zermeño, Sergio, 1978, México: Una democracia utópica: El movimiento estudiantil de 1968, México, Siglo XXI Editores; Jardon, Raúl, 1998, 1968 El fuego de la esperanza, México, Siglo XXI Editores; Rivas Ontiveros, José René, 2007, La izquierda estudiantil en la UNAM, México, Universidad Nacional Autónoma de México, Porrúa, entre otros. 
teamericano, que se expresaba fundamentalmente en contra de la guerra de Vietnam. En América Latina en particular, una de las causas ideológicas de la movilización fue el repudio al bloqueo estadounidense a Cuba y la denuncia del respaldo americano y de la Organización de Estados Americanos (OEA) a los gobiernos golpistas de la región.

Europa Oriental vio también movimientos estudiantiles en 1968: en Polonia, Yugoslavia y Checoslovaquia, este último formó parte de la llamada Primavera de Praga. ${ }^{41}$ En esta parte del mundo las luchas estudiantiles fueron también por la libertad y en contra de los valores establecidos de un statu-quo comunista que aparecían como una simulación ideológica, detrás de la promesa liberadora de los estados comunistas agazapados por las prácticas totalitarias de Estado y la vigilancia a los ciudadanos en su vida laboral y privada llevada a cabo por la redes de los partidos comunistas. ${ }^{42}$

Los movimientos estudiantiles del 68 fueron movimientos urbanos que confluyeron en las capitales de los Estados Nacionales, espacios sociales y administrativos en los cuales estaban las principales universidades e instituciones de educación superior. Parte significativa de la conducta pública que construyó la identidad de estos movimientos fueron las pintas en las bardas, huellas dejadas a su paso por las avenidas y las calles de las ciudades, frases que reescriben el nuevo texto de las ciudades, discurso permanente y efímero en el que "los muros tienen la palabra". Trazos de la nueva escritura revolucionaria que mancha y confronta la concepción de la ciudad limpia y ordenada del mundo urbano burgués, paradigma de la ciudad metropolitana y modelo de civilidad moderna. ${ }^{43}$

La nueva escritura llena de pintas los muros de las ciudades. Los boulevares revitalizados por las marchas y los gritos de los jóvenes que paran el tráfico rutinario del desarrollo post-industrial, violentan los horarios y

41 Para el significado de la primavera de Praga, véase el texto del filósofo Checo Karel Kosik, "Praga y el fin de la historia" en Vuelta, Vol. 18, número 207, feb de 1994, pp. 9-13. Véase también: Williams, Kieran, 1997, The Prague Spring and its Aftermath: Czechoslovak Politics 1968-1970, New York, Cambridge University Press. Para una introducción a los movimientos estudiantiles de Europa del Este véase: van Dijk, Ruud (editor general), 2008, Encyclopedia of the Cold War, New York, Taylor \& Francis. 2 vols. En especial las entradas: "Poland", "Czechoslovakia" y "Yugoslavia".

42 Para los movimientos estudiantiles de 1968, véase The Economist y The New York Index durante el año de 1968.

43 Para el nivel de simbolización de las pintas en los muros producidas por los sesenta y ocho véase: de Certeau, Michel, 1995, La toma de la palabra y otros escritos, México, Universidad Iberoamericana. 
vuelven a la calle y a la plaza pública el escenario de la concentración y el mitin en que queda troquelado lo nuevo, la consigna que anuncia el fin de una tradición y el ensayo de la modernidad bajo el principio de: prohibido prohibir.

La importancia de estos movimientos se expresa en la capacidad transformadora y en la reinterpretación de la historia a partir de estos eventos que contienen la densidad de las conductas individuales y colectivas. La democracia y la lucha contra el autoritarismo y el totalitarismo encontraron en las luchas estudiantiles del 68 a los creadores y escritores de las nuevas historias políticas e ideológicas que animarán las batallas durante las tres décadas siguientes.

\section{La revuelta en el Olimpo: México 1968}

El 2 de Octubre de 1968 las tropas gubernamentales mexicanas abrieron fuego sobre estudiantes que se manifestaban en la Plaza de las Tres Culturas en Tlatelolco, en la ciudad de México. El número de muertos es desconocido pero el New York Times informó de más de 300 muertos y más de 1000 heridos, ${ }^{44}$ mientras que la prensa mexicana informó que no llegaban a los 30 muertos. ${ }^{45}$ Esta acción militar del gobierno de Gustavo Díaz Ordaz no impidió que los juegos se realizaran diez días después.

44 New York Times, 24 de julio del 2004,"Cuando la intriga política eclipsó proezas deportivas" por Tim Weiner, p.2.

http:/ / www.nytimes.com/2004/07/24/sports/olympics-when-games-turned-political. $\mathrm{html}$ ?ref=timweiner

Los encabezados del jueves 3 de octubre en la prensa mexicana fueron los siguientes: Excélsior, "Recio Combate al Dispersar el Ejército un mitin de Huelguistas. 20 Muertos, 75 Heridos, 400 Presos." El Universal: “Tlatelolco, Campo de Batalla. Durante Varias Horas Terroristas y Soldados Sostuvieron Rudo Combate. 29 Muertos y más de 80 Heridos en Ambos Bandos; 1000 Detenidos." El Heraldo: "Sangriento encuentro en Tlatelolco. 26 Muertos y 71 Heridos. Francotiradores dispararon contra el Ejército: el General Toledo lesionado." EL Sol de México (Edición matutina): "Manos Extrañas se Empeñan en Desprestigiar a México. El Objetivo: Frustrar los XIX Juegos. Francotiradores Abrieron Fuego contra la Tropa en Tlatelolco. Heridos un General y 11 Militares; 2 Soldados y más de 20 civiles muertos en la peor refriega." Ovaciones: "Tiroteo en la Plaza de las 3 Culturas. Decenas de Francotiradores se enfrentaron a las Tropas. Perecieron 23 personas, 52 lesionados, mil detenidos y más vehículos quemados." Para una descripción más pormenorizada de la reacción de la prensa mexicana consultar Poniatowska, Elena, 1971, La noche de Tlatelolco. Testimonios de historia oral, México. Versión online: http://www. mapademexico.org/03r/elena_poniatowska_tlatelolco.pdf 
El 12 octubre de 1968 se inauguraron los XIX Juegos Olímpicos, en los que participaron 112 países, estos juegos representaron el final de una época, en la que hasta entonces se pensó, que estas competencias deportivas trascendían la política nacional del país sede y los conflictos internacionales de las naciones o entre los países participantes. En lugar de las competencias atléticamente puras, las olimpiadas se volvieron un nuevo ámbito de la protesta y la política, empezando por la violencia existente en México y el rechazo abierto del público asistente al presidente Gustavo Díaz Ordaz en la inauguración de los juegos -en la cual le silbaron - hecho que acontece por primera vez en la historia de México y rompe el mito de la tradición política mexicana de respeto debido al señor presidente.

Los juegos eran un escenario privilegiado, su inauguración se trasmitía en cadena mundial a través de los medios. La inauguración y el desarrollo de los juegos fueron vistas y escuchadas por 600 millones de personas ${ }^{46} \mathrm{y}$ leídas en las crónicas deportivas y en esta ocasión políticas, por muchos más. La cobertura informativa mundial, aunada a la herida por bala en la plaza de Tlatelolco a la periodista italiana Oriana Fallaci, ${ }^{47}$ quien destapó la masacre y rompió el cerco del silencio tendido por el gobierno mexicano, al tiempo que recibió la solidaridad mundial de sus colegas periodistas y estimuló la ampliación informativa y de reportajes sobre México. Esos eventos rompieron la idea de excepción política mexicana y colocaron al país en el mismo nivel de autoritarismo y violencia que el de los otros países de la región latinoamericana.

En la mañana del 16 de octubre, en el podio de premiación ocurrió un acto de protesta que marcó la histórica de las olimpiadas. El atleta estadounidense Tommie Smith, ganó la medalla de oro, luego de haber roto el récord olímpico en la carrera de los 200 metros, el australiano Peter Norman obtuvo el segundo lugar y el también estadounidense John Carlos la tercera plaza. ${ }^{48}$ Los dos velocistas afroamericanos, se presentaron en el pódium descalzos, inclinaron la cabeza y levantaron los puños envueltos en guan-

46 Comité Organizador de los XIX Juegos Olímpicos, Tomo II, p.301

47 Oriana Fallaci fue herida en los acontecimientos del 2 de octubre en México, ella misma publicó su experiencia, primero en la revista norteamericana Look el 12 de noviembre de 1968 y después en México en el periódico La Voz de México. Órgano central del Partido Comunista Mexicano el 1 de diciembre de 1968.

Véase la ceremonia de premiación en: http:/ / www.youtube.com/watch?v=ocu-llaGEnY W2k\&pbx=1\&bav=on.2,or.r_qf.\&bvm=bv.48293060,d.ZWU\&fp=de401e2b82443a47\&biw $=10$ 00\&bih $=435$ consultado 23 junio 2013. 
tes negros mientras sonaba el himno nacional estadounidense, en señal de protesta en contra de la pobreza y el racismo existente en los Estados Unidos, el gesto apareció al día siguiente en la primera plana de todos los periódicos del mundo.

El Comité Olímpico Internacional consideró la protesta inadecuada para el ambiente apolítico de las olimpiadas. Un portavoz de la organización olímpica afirmó que era "una deliberada y violenta infracción de los principios fundamentales del espíritu olímpico". ${ }^{49}$ Smith y Carlos fueron suspendidos del equipo olímpico estadounidense y fueron expulsados de los juegos olímpicos, y oficialmente se les quitaron las medallas que habían ganado. ${ }^{50}$

La otra manifestación de protesta la protagonizó Vera Caslavska, gimnasta checoslovaca, que en abril de 1968 en plena Primavera de Praga (del 5 de enero hasta el 20 de agosto de 1968) había firmado el manifiesto "Dos mil palabras" 51 , texto del escritor checo Ludvk Vaculk publicado el 27 de junio. El manifiesto denunciaba la dominación soviética de su país. Por temor a ser arrestada, Caslavska se refugió en las montañas, manteniéndose en forma practicando su rutina de ejercicios de piso al aire libre.

Vera Caslavska considerada la mejor gimnasta del mundo, ganó cuatro medallas de oro y dos de plata por equipo. En la prueba de suelo, un ajuste de puntaje de último minuto resultó en un empate por una de las medallas de oro entre la checoslovaca y la gimnasta soviética Larissa Latynina. En ambas ceremonias de premiación, cuando se tocó el himno Soviético, Caslavska inclinó su cabeza con su mirada hacia abajo y con el rostro hacia otro lado en dirección opuesta a las competidoras de la URSS en signo de desafío hacia Moscú.

Ese acto marcó el final de su carrera competitiva. El gobierno checo le prohibió su participación en cualquier evento deportivo, viajar al extranjero y competir dentro y fuera de Checoslovaquia así como la publicación de su autobiografía. Tras la caída del comunismo, Caslavska llegó a ser

49 Churchill, James E. Jr.(ed.), 1983, The Olympic Story, New York: Associated Press and Grolier Enterprises.

50

Sobre la protesta de Smith:

http://news.bbc.co.uk/onthisday/hi/dates/stories/october/17/newsid_3535000/3535348. stm. Sobre la vida de Tommie Smith véase: http:/ / www.tommiesmith.com/bio.html y http:/ / www.lanacion.com.ar/1057202-el-black-power-de-mexico-68-40-anos-despues

51 Para consultar el manifiesto (en inglés), véase: http:/ / library.thinkquest.org/C001155/documents/doc26.htm 
consejera del primer presidente de la República Checa Václav Havel en asuntos del deporte, educación, salud y trabajo social.

\section{Epílogo}

Las olimpiadas en México, celebradas entre el 12 y el 27 de octubre de 1968, fueron un tiempo oficial, nacional e internacional, fijado por el compromiso del gobierno mexicano con un organismo que aglutinaba a 112 países. Este evento mundial en el interior de México, fue el primero de su tipo en América Latina, en un país en vías de desarrollo y de habla hispana. En esta olimpiada, que rebosaba excepcionalidad, participaron 5,530 atletas y concurrieron cientos de periodistas, quienes durante más de quince días, dieron una cobertura informativa universal. Esta densidad internacional, dentro de las fronteras de la sociedad Nacional, desbordó los recursos políticos e institucionales del Estado y rompió la tradición heredada de control informativo que había construido el Estado centralizado y regulador de la vida social durante el régimen político de la Revolución Mexicana, componente propio de los regímenes totalitarios, autoritarios y populistas latinoamericanos que edificaron mecanismos de control y corrupción sobre los medios de comunicación masiva, control que había logrado aislar la información al mundo externo y seleccionar la "verdad oficial" difundida a los ciudadanos.

El movimiento estudiantil mexicano fue un proceso político paralelo a los movimientos estudiantiles de otros países, condición de paralelismo histórico que le dio elementos de identidad cultural y visibilidad mundial que desbordó el cerco impuesto por las fronteras nacionales. A la condición de correspondencia histórica, el 68 mexicano estuvo inmerso en la lógica político administrativa del Estado dada por el evento mundial de las olimpiadas que fijó al movimiento social un límite temporal en sus negociaciones con el gobierno -12 de octubre de 1968 - en esta condición de tiempo político gubernamental los dirigentes estudiantiles creyeron contar con recursos a su favor frente al gobierno mexicano, quien apeló al expediente autoritario de la represión violenta al que había recurrido a lo largo de su historia como régimen político de la Revolución Mexicana, represión militar cuyo saldo en muertos fue mayor que la Primavera de Praga y cuyo efecto resquebrajó los recursos políticos e ideológicos del régimen ante una sociedad modernizada, urbana y abierta, frente a la cual el gobierno no pudo continuar la reproducción del régimen que había garantizado una estabilidad política ampliamente acreditada y aún vigente al principio de los años sesenta. 
Los movimientos estudiantiles fueron procesos nacionales que tuvieron su dinámica propia, pero que en el paralelismo con los otros movimientos estudiantiles de carácter nacional construyeron su condición global y semejante, característica que fue comparada y mutuamente influenciable por los actores políticos participantes durante el tiempo particular de cada movimiento estudiantil, tanto en política como ideológicamente. Esta condición internacional general, que se expresó particularmente en cada nación, fijó la densidad simbólica del 68 en la historia del siglo XX y la posibilidad de su significado en cada uno de sus procesos políticos nacionales.

Estos movimientos juveniles, de carácter cultural, contestatarios y utópicos mostraban un conjunto de nuevos actores sociales en ascenso, cuya acción colectiva y demandas culturales e ideológicas rompieron las tradiciones políticas generales y particulares edificadas en la segunda posguerra del siglo XX. El año de 1968 fue en términos globales, la evidencia de un límite, una frontera histórica franqueada por la acción colectiva de los nuevos actores sociales, cuyas demandas mostraron una nueva composición social en las sociedades nacionales. Esta condición de cambio se expresó en el desarrollo de cada uno de los movimientos sociales, cuyo significado global es el del agotamiento de una época compartida como referente internacional ineludible en cada una de las sociedades y Estados en conflicto, movimientos sociales que compartieron, en cada país, referentes internacionales de identidad, representación social y política, en los que se hizo claro el desfase existente entre la sociedad de los sesenta y los regímenes políticos construidos durante la posguerra y que dieron sentido y contenido culturales de credibilidad a la Guerra Fría.

\section{Bibliografía}

Adam, Barry, 1987, The rise of a gay and lesbian movement, London, G. K. Hall \& Co.

Bambirra, Vania, 1971, Diez años de insurrección en América Latina, Chile, Ediciones Prensa Latinoamericana, 2 Tomos.

Bell, Daniel, 1988, The End of Ideology. On the Exhaustion of Political Ideas in the Fifties, Cambridge, Massachusetts, Harvard University Press.

Bell, Daniel, 1976, The Contradictions of Capitalism, New York, Basic Books.

Bell, Daniel, 1973, The Coming of the Post-industrial Society, NewYork, Basic Books. 
Benz, Wolfagang y Graml Germann, 1998, El Siglo XX. Europa después de la Segunda Guerra Mundial, Tomo 2, México, Siglo XXI Editores.

Boils, Guillermo, Aurora Loyo y Ricardo Pozas Horcasitas, 1974, Cronología de la Violencia política, 1945-1970, México, I.I.S - UNAM, 2 Tomos.

Breitman, George, (ed.), 1966, Malcolm X Speaks, New York, Grove Press.

Carter, David, 2004, Stonewall: The Riots that Sparked the Gay Revolution, New York, St. Martin's Press.

Crouzet, Maurice, 1961, L'Epoque contemporaine. À la recherche d'une civilisation nouvelle, Paris, Presses Universitaires de France.

Duverger Maurice, 1952, Les régimes politiques, Paris, Presses Universitaires de France.

Ferro, Marc, 1992, Suez: naissance d'un Tiers Monde, Paris, Éditions Complexe.

Galbraith, John Kenneth, 1992, La sociedad opulenta, España, Editorial Planeta-Agostini.

Gordon, Sara, 1979, Cronología de las intervenciones extranjeras, 5 tomos, México, FCPS, UNAM.

Gurvitch, Georges, compilador, 1958, Traité de sociologie, Paris, Presses Universitaires de France.

Johnson, Paul, 1983, A History of the Modern World, London, Weidenfeld and Nicolson Ltd.

Kaser, Michael Charles, 1976, Health Care in the Soviet Union and Eastern Europe, London, Taylor \& Francis.

Kaspi, André, 2002, Les Américains, Tomo 2, Paris, Éditions du Seuil.

Kennedy, F. Robert, 1969, Thirteen days: A memoire of the Cuban Missile Crisis, New York, Norton \& Company.

King, Martin Luther Jr., 1964, Why We Cant'n Wait, New York, Harper and Row.

King, Martin Luther Jr., 1967, Where Do We Go from Here: Chaos or community?, Boston, Massachusetts, Beacon Press 
Kosik, Karel, 1994, "Praga y el fin de la historia”, Vuelta, vol. 18.

Landon, Jones, 1980, Great Expectations: America and the Baby Boom Generation. Book Surge Publishing, New York: Coward, McCann \& Geoghegan.

Linz J., 1964, “An Authoritarian Regime: Spain, an Authoritarian Regime” en E. Allard e Y. Littunen (comps). Cleavages, Ideologies and Party Systems: Contributions to Comparative Political Sociology, Helsinki, Westermarck Society.

Linz, Juan, 1975, “Totalitarian and authoritarian regimes”, en F.L. Greenstein y N.W. Polsby (comps), Handbook of Political Science, Boston, Massachusetts, AddisonWesley.

Marcuse, Herbert, 1955, Eros and Civilization, Boston, Massachusetts, Beacon Press.

Marcuse, Herbert, 1958, Soviet Marxism. A Critical Analysis, New York, Columbia University Press.

Marcuse, Herbert, 1964, One Dimensional Man, Boston, Massachusetts, Beacon Press.

Malcolm X, 1965, The autobiography of Malcolm X, New York, Grove Press.

Meschonnic, Henri, 1988, Modernité, modernité, Paris, Editions Verdier.

Myrdal, Gunnar, 1960, Beyond the Welfare State: Economic Planning and its International Implications, London, Duckworth.

Myrdal, Gunnar, 1963, Challenge to Affluence, New York, Random House.

O’Donnell, Guillermo y C. Schmitter, 1988, Transiciones desde un gobierno autoritario, Buenos Aires, Paidós.

Pasquale Villani, 1997, L' età contemporanea, Italia, il Mulino.

Pozas Horcasitas, Ricardo, 2013, “El autor moderno y la escritura," Revista Mexicana de Sociología, num. 2, México, IIS, UNAM, pp.226-253.

Pozas Horcasitas, Ricardo, 2006, Los nudos del tiempo, la modernidad desbordada, México, Siglo XXI Editores.

Procacci, Giuliano, 2001, Historia General del siglo XX, Barcelona, Crítica, Barcelona. 
Raleigh, Donald J., 2002, Soviet Baby Boomers. An Oral History of Russia's Cold War Generation, Oxford, Oxford University Press.

Roszak, Theodore, 1995, The Making of a Counter Culture, California, University of California Press.

Sauvy, Alfred, 1969, La montée des jeunes, Paris, Calmann-Lévy.

Simmel, Georg, 1977, Estudios sobre las formas de socialización, Madrid, Alianza Editorial.

Solana, Fernando y Comesaña Maríangeles, 2008, Evocación del 68, México, Siglo XXI Editores.

Touraine, Alain, 1969, La Société post-industrielle, Paris, Éditions Denoël.

Touraine, Alain, 1968, Le Mouvement de mai ou le communisme utopique, Paris, Éditions du Seuil.

Touraine, Alain, 1973, La production de la Société, Paris, Éditions du Seuil.

Wolff, Robert Paul, Barrington Moore Jr. y Herbert Marcuse, 1969, A Critique of Pure Tolerance, Boston, Massachusetts, Beacon Press.

Recibido el 17 de octubre de 2013 Aceptado el 6 de diciembre de 2013 